Research Article

\title{
Optimization of VEDs for Vibration Control of Transmission Line Tower
}

\author{
Guoping Huang $\mathbb{D}^{1,},{ }^{1,2}$ Jianhua Hu $\mathbb{D}^{\circ},{ }^{3}$ Yuzhu He, ${ }^{2}$ Haibo Liu $\mathbb{D}^{\circ},{ }^{3}$ and Xiugui Sun ${ }^{4}$ \\ ${ }^{1}$ College of Civil Engineering, Hunan City University, Yiyang 413000, China \\ ${ }^{2}$ College of Civil Engineering, Hunan University, Changsha 410082, China \\ ${ }^{3}$ Hunan Communication \& Water Conservancy Group Ltd., Changsha 410008, China \\ ${ }^{4}$ Hunan Provincial Communications Planning Survey \& Design Istute Co, Ltd., Changsha 410200, China \\ Correspondence should be addressed to Jianhua Hu; master_hjh@163.com and Haibo Liu; 17120365@qq.com
}

Received 30 August 2021; Accepted 7 October 2021; Published 19 October 2021

Academic Editor: Nan Zhang

Copyright (C) 2021 Guoping Huang et al. This is an open access article distributed under the Creative Commons Attribution License, which permits unrestricted use, distribution, and reproduction in any medium, provided the original work is properly cited.

\begin{abstract}
This paper investigates the optimization of viscoelastic dampers (VEDs) for vibration control of a transmission line tower. Considering the stiffness of the steel brace connected to a VED, the mechanical model of the VED-brace system was established. Subsequently, the additional modal damping ratio of the transmission line tower attached with VEDs was obtained analytically. Furthermore, the finite element model of a two-circuit transmission line tower with VEDs was built in ANSYS software, and the influences of installation positions and parameters of VEDs on the additional modal damping ratio were clarified. In addition, the control performance of VEDs on the transmission line tower subjected to wind excitations was emphatically illustrated. The results show that the stiffness of the steel brace connected to a VED has a significant effect on the maximum additional modal damping ratio of the VED-brace system provided for the transmission line tower and the optimal parameters of the VED. Meanwhile, the installation positions of VEDs dramatically influence the additional modal damping ratio. Moreover, the increase of the brace stiffness and the loss factor is beneficial to improve the control performance of VEDs. Besides that, the VEDs present superior control performance on the top displacement of the transmission line tower as well as the transverse bending vibration energy.
\end{abstract}

\section{Introduction}

Transmission line tower is one of the typical high-rise structures, which is widely used throughout the world for energy supplying $[1,2]$. The transmission line tower is vulnerable to suffering from wind-induced vibrations owing to its high flexibility and low inherent damping characteristics [3-5]. Frequent and excessive vibration could potentially induce damage and even collapse of the transmission line tower and have adverse effects on the serviceability of the whole transmission tower-line system [6-8]. Considerable investigations focused on theoretical [9-11], experimental [12-14], and field measurement [15] have been carried out in recent decades, which is devoted to mitigating the dynamic responses of the line transmission tower. To guarantee the normal operation of the transmission line tower, several measures have been proposed for the vibration control of the transmission line tower, which mainly include increasing the stiffness of the transmission line tower $[16,17]$ and attaching energy dissipation devices on the transmission line tower.

Attaching energy dissipation devices is a commonly used method for mitigating vibrations of the transmission line tower [18-20]. The tuned mass damper (TMD) is a typical energy dissipation device, which has been commonly utilized for mitigating vibrations of high-rise structures $[21,22]$. It has been found that the application of TMDs helps reduce the dynamic responses of the transmission line tower [23-25]. However, the disadvantage is that several additional masses should be installed on top of a 
transmission tower, which requires the occupancy of the structural space. To overcome the shortcomings of the TMD, several energy-dissipating dampers were further proposed to enhance the vibration control performance of the transmission line tower. The magnetorheological (MR) damper has been successfully used on suppressing the wind-induced response of a real transmission line tower [26]. It has shown that the MR damper with optimally designed parameters has some advantages in controlling the wind-induced response of the transmission line tower. Nevertheless, the MR damper is quite complicated, and the requirement in the additional energy supply during the vibration control process is unrealistic while accepting strong excitations. Besides that, the passive friction dampers have been used in a finite element tower model with lumped mass, which is further applied in a real transmission line tower for verifying its superior control performance [27]. In addition, the use of viscoelastic dampers (VEDs) for the wind-resistant design of the transmission line tower has also been proposed [28]. Note that the optimal design of VEDs for vibration control of the transmission line tower has not been investigated.

This paper investigates the optimal design of VEDs for vibration control of a transmission line tower subjected to wind excitations. The paper is organized as follows. Firstly, the mechanical model of the VED-brace system was established. Subsequently, the maximum additional modal damping ratio of the transmission line tower attached with VEDs was calculated. Next, based on the finite element model of a two-circuit transmission line tower with VEDs, the influences of installation positions and parameters of VEDs on the additional modal damping ratio were clarified. Finally, the control performance of VEDs on the transmission line tower subjected to wind excitations was numerically demonstrated.

\section{Model of VED-Brace System and Optimal Design of VED}

2.1. Mechanical Model of the VED-Brace System. A coupled system combined with a viscoelastic damper and a supported steel brace, also denoted as VED-brace system, is shown in Figure 1. The VED is represented by a parallel spring (with stiffness $K_{d}$ ) and damper (with damping coefficient $C_{d}$ ), while the supported steel brace, connected to the VED and primary structure, is modeled by a spring with stiffness $K_{b}$ and in series with the VED. Assuming that a sinusoidal displacement $u(t)=$ $u_{0} \sin \omega t$ with amplitude $u_{0}$ and natural frequency $\omega$ is applied on the VED, its output force is given as

$$
F_{d}(t)=K_{d} u(t)+C_{d} \dot{u}(t),
$$

where $\dot{u}(t)$ denotes the first-order derivative of $u(t)$ with time $t$.

Introducing the energy dissipation stiffness of VED as $K_{d}^{\prime}=C_{d} \omega$, the output force of the VED can be rewritten as

$$
F_{d}(t)=K_{d} u_{0} \sin (\omega t)+K_{d}^{\prime} u_{0} \cos (\omega t) .
$$

Supposing that the displacement of the VED-brace system is represented by $u_{A}=u_{a} \sin \omega t$, the displacement of the VED and the brace can be expressed as

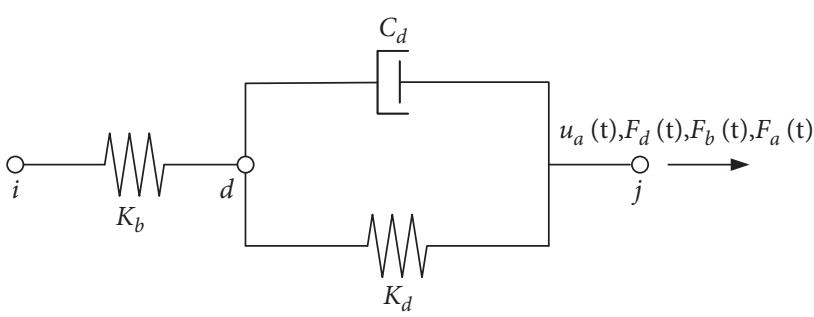

Figure 1: Mechanical Model of the VED-brace system.

$$
\begin{aligned}
& u_{D}=u_{d} \sin (\omega t-\varphi), \\
& u_{B}=u_{A}-u_{D},
\end{aligned}
$$

where $\varphi$ is the displacement phase difference between the VED and the brace.

Based on the equality of internal force for the series system, we obtain

$$
\begin{aligned}
F_{b}(t) & =F_{d}(t) \\
& =F_{a}(t) \\
& =K_{a} u_{a} \sin \omega t+K_{a}^{\prime} u_{a} \cos \omega t,
\end{aligned}
$$

where

$$
\begin{aligned}
& K_{a}=\frac{\left(K_{b}+K_{d}\right) K_{b} K_{d}+K_{b}\left(K_{d}^{\prime}\right)^{2}}{\left(K_{b}+K_{d}\right)^{2}+\left(K_{d}^{\prime}\right)^{2}}, \\
& K_{a}^{\prime}=\frac{K_{b}^{2} K_{d}^{\prime}}{\left(K_{b}+K_{d}\right)^{2}+\left(K_{d}^{\prime}\right)^{2}} .
\end{aligned}
$$

The ratio of the relative displacement amplitude at both ends of the VED to the relative displacement amplitude at both ends of the VED-brace system is expressed as

$$
\begin{aligned}
\beta & =\frac{u_{d}}{u_{a}} \\
& =\frac{K_{b}}{\sqrt{\left(K_{b}+K_{d}\right)^{2}+\left(K_{d}^{\prime}\right)^{2}}} .
\end{aligned}
$$

According to equation (7), it is straightforward to see that the ratio $\beta$ approaches 1 if the brace stiffness $K_{b}$ is sufficiently large. Otherwise, the effect of the limited stiffness of the steel brace must be included during vibration control analysis. For the convenience of analysis, the nondimensional parameters are introduced here:

$$
\begin{array}{r}
\eta=\frac{K^{\prime}}{K_{d}}, \\
\alpha=\frac{K_{b}}{K_{d}}, \\
\alpha_{1}=\frac{K_{a}}{K_{d}} \\
\alpha_{2}=\frac{K_{a}^{\prime}}{K_{d}},
\end{array}
$$


where $\alpha$ denotes the ratio of the brace stiffness to the damper stiffness; $\alpha_{1}$ is the ratio of the energy storage stiffness of the VED-brace system to the energy storage stiffness of the VED; $\alpha_{2}$ denotes the ratio of the energy dissipation stiffness of the VED-brace system to the energy storage stiffness of the VED; $\eta$ denotes the loss factor of the VED, and its typical value ranges from 0.2 to 5.0 .

Figure 2 shows the variations of $\beta, \alpha_{1}$, and $\alpha_{2}$ with respect to the stiffness ratio $\alpha$. It can be seen from Figure 2(a) that $\beta$ increases with $\alpha$ and will eventually converge to 1 , which means that increasing the brace stiffness is beneficial to improve the energy dissipation efficiency of the VED. As shown in Figure 2(b), when $\alpha$ is greater than 2, $\alpha_{1}$ will be greater than 1 , and $K_{a}$ finally converges to $K_{d}$ as $K_{b}$ continues to increase. In this case, the brace can be regarded as a rigid rod, indicating that the energy storage stiffness of the VED-brace system is equal to the energy dissipation stiffness of the VED. It can be found in Figure 2(c) that $\alpha_{2}$ increases with $\alpha$. Moreover, $K_{a}^{\prime}$ finally converges to $K_{d}$ as $\alpha$ grows, which can be considered that the energy dissipation stiffness of the VED-brace system is also equal to that of the VED.

2.2. Optimal Design of VED. The simplified model of the tower segment with the VED-brace system is depicted in Figure 3 . Note that the VED-brace system is connected in parallel to the main member of the transmission line tower.

Assume the relative displacement of both the $i$ end and $j$ end of the tower segment as

$$
u(t)=u_{\max } \sin \omega t .
$$

For the tower segment coupled with the VED-brace system, the output force becomes

$$
\begin{aligned}
F(t) & =F_{f}(t)+F_{a}(t) \\
& =\left(K_{f}+K_{a}\right) u_{\max } \sin \omega t+K_{a}^{\prime} u_{\max } \cos \omega t .
\end{aligned}
$$

The equivalent damping ratio for the tower segment may be obtained as

$$
\begin{aligned}
\xi_{a} & =\frac{E_{d}}{4 \pi E_{s}} \\
& =\frac{K_{a}^{\prime}}{2\left(K_{f}+K_{a}\right)} .
\end{aligned}
$$

By defining the additional stiffness ratio $\alpha_{a}=K_{a} / K_{f}$, equation (10) can be rewritten as

$$
F(t)=u_{\max } K_{f}\left(1+\alpha_{a}\right) \sin \left(\sin \omega t+2 \xi_{a} \cos \omega t\right),
$$

where

$$
\begin{aligned}
& \alpha_{a}=\alpha_{b} \alpha_{d} \frac{\alpha_{b} \eta+\left(1+\eta^{2}\right) \alpha_{d}}{\left(\alpha_{b} \eta+\alpha_{d}\right)^{2}+\eta^{2} \alpha_{d}^{2}}, \\
& \xi_{a}=\frac{1}{2} \frac{\alpha_{b}^{2} \eta^{2} \alpha_{d}}{\left(\alpha_{b} \eta+\alpha_{d}\right)\left(\alpha_{b} \eta+\alpha_{b} \alpha_{d}+\alpha_{d}\right)+\left(1+\alpha_{b}\right) \alpha_{d}^{2} \eta^{2}},
\end{aligned}
$$

where $\alpha_{b}=K_{b} / K_{f}$ represents the ratio of the brace stiffness to the tower segment stiffness; $\alpha_{d}=K_{d}^{\prime} / K_{f}$ represents the energy dissipation stiffness ratio of the VED.

From equations (12a) to (12c), it is shown that $\alpha_{a}$ and $\xi_{a}$ are dependent on $\alpha_{b}, \alpha_{d}$, and $\eta$. Again, $\eta$ is taken as 1.4. Figure 4 shows the variations of the stiffness ratio $\alpha_{a}$ with respect to $\alpha_{d}$ under various $\alpha_{b}$. It is apparent that the stiffness ratio $\alpha_{a}$ increases with the increase of $\alpha_{d}$ and approaches $\alpha_{b}$ for a large $\alpha_{d}$. This is because extremely large damper stiffness will lock the damper, which causes the damper to fail to dissipate the vibration energy. The variations of the equivalent damping ratio $\xi_{a}$ with respect to $\alpha_{d}$ under various $\alpha_{b}$ are further illustrated in Figure 5. Note that the equivalent damping ratio $\xi_{a}$ firstly increases with the increase with $\alpha_{d}$, reaching the maximum value when the $\alpha_{d}$ reaches a certain value, and then decreases with the increase of $\alpha_{d}$.

By taking the derivatives of the damping ratio $\xi_{a}$ with respect to $\alpha_{d}$, there is

$$
\xi_{a}=\frac{1}{2} \frac{\alpha_{b}{ }^{2} \eta^{2}}{\left(1+\eta^{2}\right)\left(1+\alpha_{b}\right) \alpha_{d}+\alpha_{b}^{2} \eta^{2} / \alpha_{d}+\alpha_{b}{ }^{2} \eta+2 \alpha_{b} \eta} .
$$

By defining $f\left(\alpha_{d}\right)=\left(1+\eta^{2}\right)\left(1+\alpha_{b}\right) \alpha_{d}+\alpha_{b}{ }^{2} \eta^{2} / \alpha_{d}$ and letting $\partial f\left(\alpha_{d}\right) / \alpha_{d}=0$, we obtain

$$
\alpha_{d}=\frac{\alpha_{b} \eta}{\sqrt{\left(1+\eta^{2}\right)\left(1+\alpha_{b}\right)}} .
$$

Substituting equations (14) into equation (12c), the peak damping ratio is derived as

$$
\xi_{a, \text { peak }}=\frac{1}{4} \frac{\alpha_{b} \eta}{\sqrt{\left(1+\alpha_{b}\right)\left(1+\eta^{2}\right)+1+\alpha_{b} / 2}} .
$$

The variations of the peak damping ratio $\xi_{a \text {,peak }}$ with respect to the stiffness ratio $\alpha_{b}$ for $\eta=1.4$ and loss factor $\eta$ for $\alpha_{b}=0.2$ are illustrated in Figure 6. As shown in Figure 6, the peak damping ratio $\xi_{a \text {,peak }}$ increases with the increase of stiffness ratio $\alpha_{b}$ and loss factor $\eta$. In summary, equation (15) describes peak damping ratio for the tower segment when equation (14) is fulfilled. These two equations constitute the optimal parameter design for VEDs in the transmission line tower.

After the brace stiffness $K_{b}$ and the loss factor $\eta$ of the VED are determined, the damping ratio of the energy dissipation system reaches the maximum value. The ratio of the equivalent 


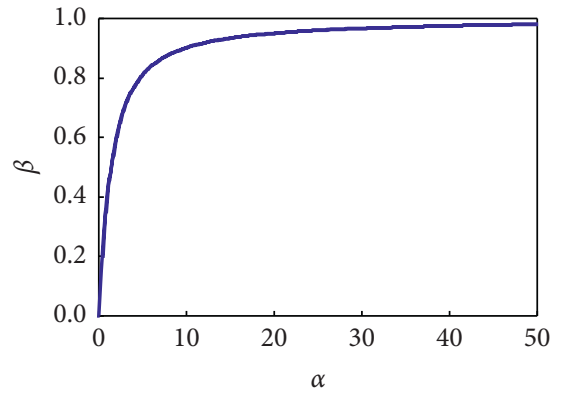

(a)

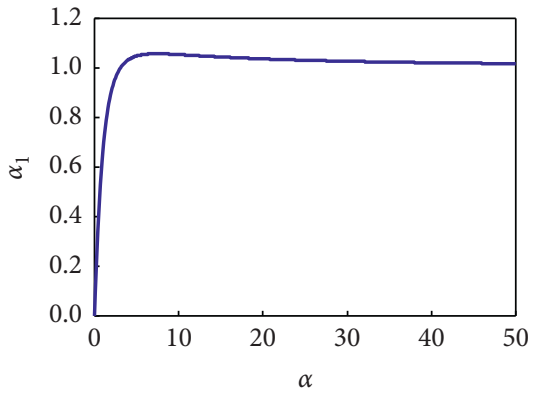

(b)

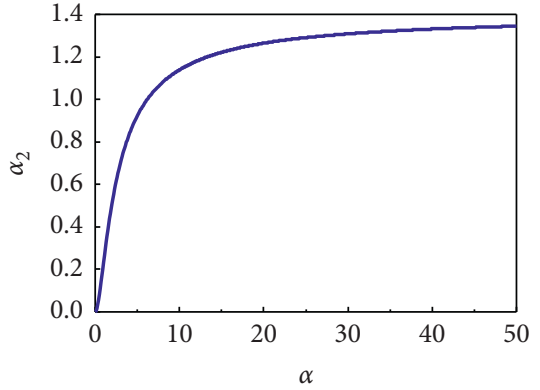

(c)

Figure 2: Variations of $\beta, \alpha_{1}, \alpha_{2}$ with the stiffness ratio $\alpha$ for $\eta=1.4$.

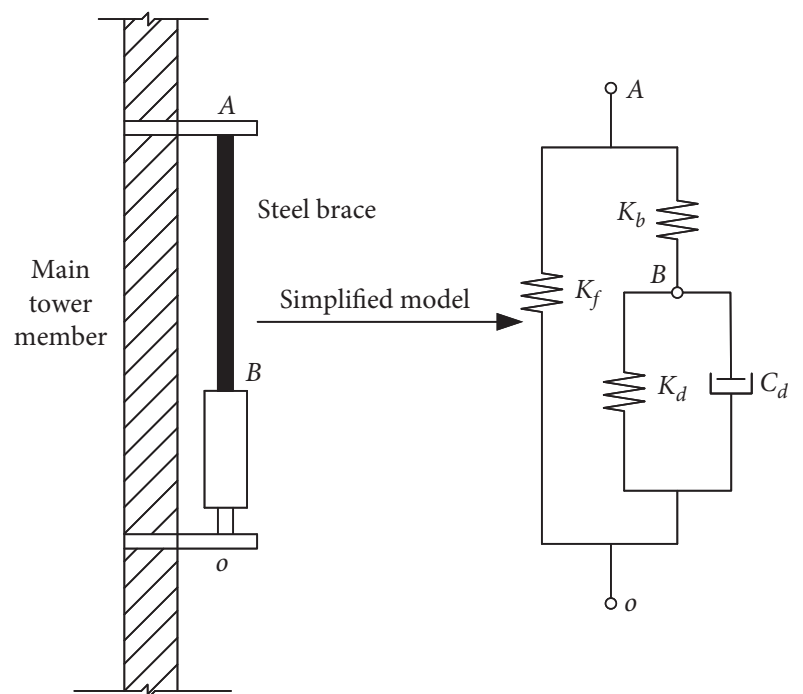

FIGURE 3: Simplified model of the tower segment with the VEDbrace system.

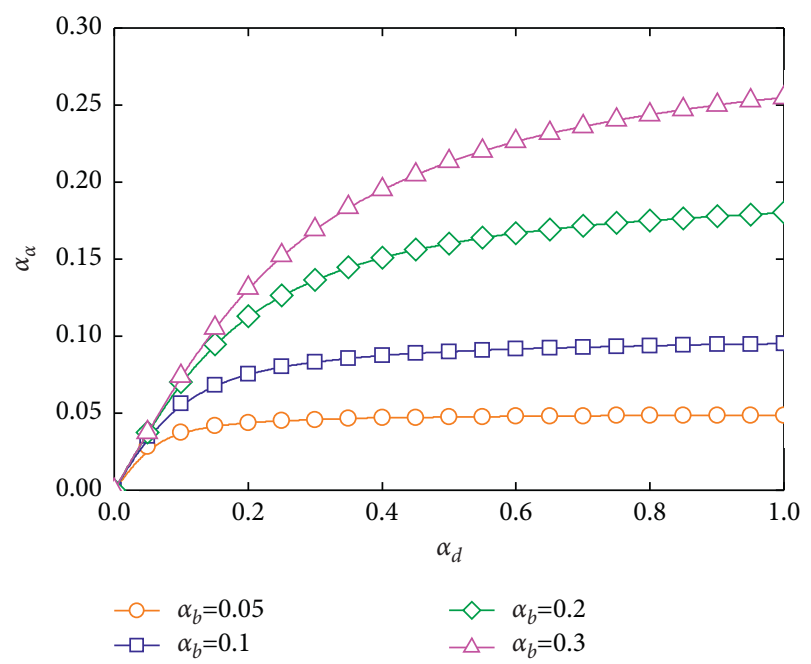

FIgURE 4: Variations of the stiffness ratio $\alpha_{a}$ with respect to $\alpha_{d}$ under various $\alpha_{b}$.

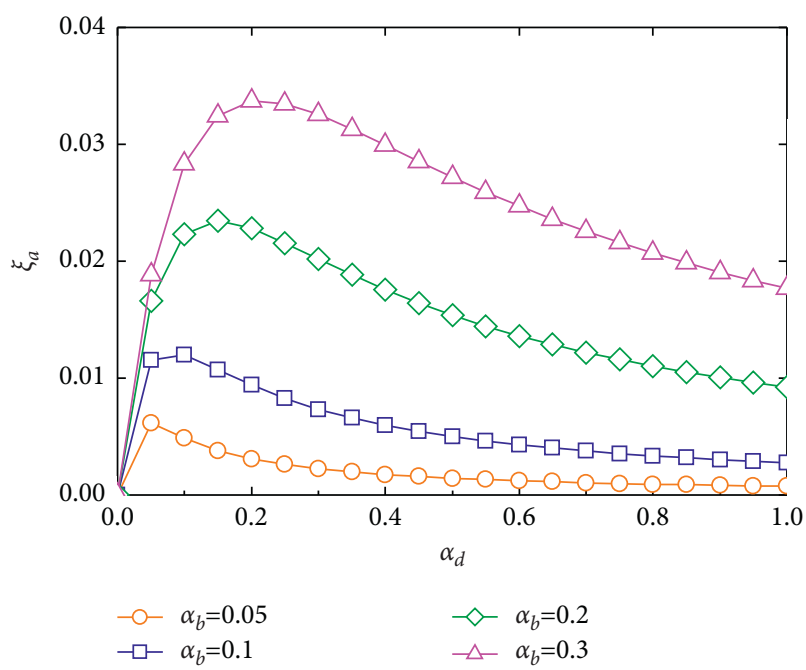

Figure 5: Variations of the equivalent damping ratio $\xi_{a}$ with respect to $\alpha_{d}$ under various $\alpha_{b}$.

energy storage stiffness $K_{d}$ of the VED to the brace stiffness $K_{b}$ can be calculated by the following formula as

$$
\lambda=\sqrt{\frac{1}{\left(1+\eta^{2}\right)\left(1+\alpha_{b}\right)}} .
$$

It should be noted that when the additional modal damping ratio of the VED-brace system reteaches maximum, its energy dissipation efficiency is also the largest. Thus, the optimal parameters of the VED-brace system can be determined by equations (14) and (16), and the maximum additional modal damping ratio of the tower section can be calculated by equation (15).

\section{Numerical Simulation of a Transmission Line Tower with VEDs}

3.1. Finite Element Model of Transmission Line Tower. To investigate the vibration control performance of VEDs for a transmission line tower, a three-dimensional finite element 


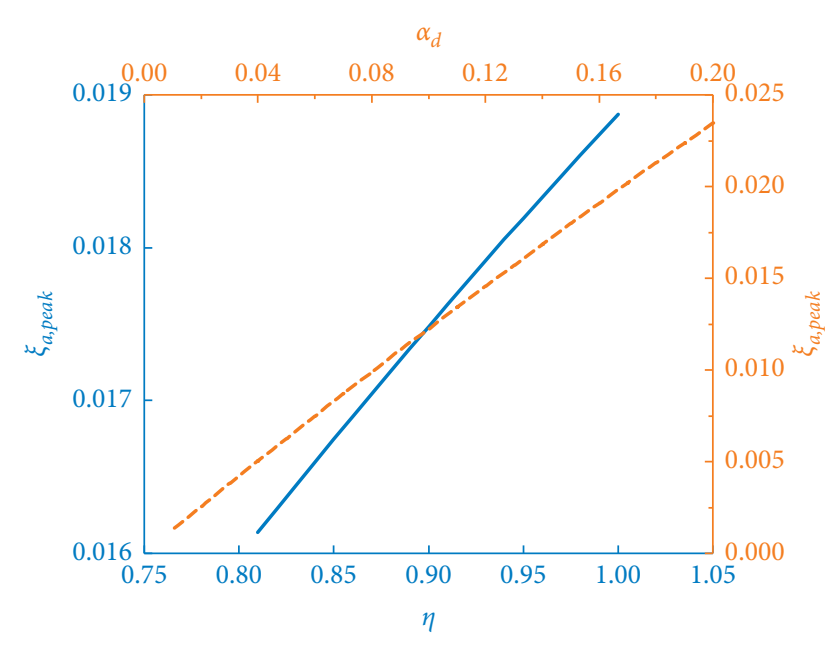

FIGURE 6: Variations of the peak damping ratio $\xi_{a \text {,peak }}$ with respect to $\alpha_{b}$ and $\eta$.

model of a two-circuit transmission line tower shown in Figure 7 is built in ANSYS software. The transmission line tower height is $103.6 \mathrm{~m}$, and two cross arms are symmetrically arranged at the heights of $57 \mathrm{~m}, 78.2 \mathrm{~m}$, and $99.6 \mathrm{~m}$ above the ground. The end of the cross arm is $16.6 \mathrm{~m}, 17.6 \mathrm{~m}$, and $20.22 \mathrm{~m}$ away from the center of the transmission tower, respectively. The main structure of the transmission line tower is composed of steel pipes and connected with highstrength bolts. The cross section of the steel pipe is varied with height of the transmission line tower. The most important stressed components are the four tower columns, and their cross-sectional area decreases from bottom to top. The main material parameters of members are as follows: elastic modulus $206 \mathrm{GPa}$, density $7850 \mathrm{~kg} / \mathrm{m}^{3}$, and Poisson's ratio 0.3 .

The spatial beam element BEAM188 is used for each member, without considering the coupling vibration of the conductor, ground wire, and transmission tower. The transmission line tower without control consists of 527 nodes and 1406 elements in total. The overall coordinate system is divided into the horizontal $X$ axis, the forward $Y$ axis, and the $Z$ axis along with the tower height. The origin of coordinates is at the midpoint of the bottom of the tower. The first three mode shapes of the transmission tower are obtained by modal analysis, as illustrated in Figure 8 . The first mode shape is the bending vibration mode perpendicular to the conductor direction, the second mode shape is the bending vibration mode along the conductor direction, and the third mode shape is the torsional vibration mode rotating around the centerline of the tower. Based on the finite element model of the transmission tower, the modal analysis of the transmission tower is carried out, and the properties of the transmission line tower shown in Table 1 are further obtained.

3.2. The Installation Position of VED. Figure 9 presents the strain energy distribution in the transmission tower for the first second mode. It can be seen from Figure 9(a) that the first modal strain energy of the primary members is much greater than that of the inclined bars and the cross arms, and the first modal strain energy of the lower part of the tower legs is also greater than that of the upper parts. As shown in Figure 9(b), the distribution law of the second modal strain energy in the transmission tower is consistent with that of the first modal strain energy. Thus, the VEDs should be installed on the lower primary members with the largest possible modal strain energy, which helps to efficiently control the vibration of the transmission line tower for the first two modes.

The main tower columns with the same function are recorded as a unit, and there are 72 main tower column units numbered from bottom to top of the transmission line tower. The axial deformation of each main tower column for the first mode is shown in Table 2. The variations of the axial deformation with the unit number are further illustrated in Figure 10. Note that the large deformation occurs at the 1, 2, $3,4,21,22,23,25$, and 49 units of the transmission line tower. To effectively control the bending and the axial deformation of the transmission line tower, the installation positions of VEDs need to be taken into account in combination with the data in Table 2 and Figure 10. There are mainly two installation schemes: scheme 1 is to install VEDs on the tower column unit with large axial deformation, and scheme 2 is to install the same number VEDs with the same parameters as scheme 1 on the tower column unit from the bottom to top of the transmission line tower. 44 VEDs used in installation scheme 1 are installed in parallel on the four main tower columns of the transmission tower, and 44 VEDs used in installation scheme 2 are installed on the tower column unit from bottom to top of the transmission line tower. Note that the unit numbers of VEDs corresponding to installation scheme 1 and installation scheme 2 are shown in Table 3.

3.3. The Optimal Parameters of VED. The outer diameters of the circular steel pipes of the main tower columns of the transmission tower vary from $109.5 \mathrm{~mm}$ to $213 \mathrm{~mm}$, and the wall thickness of the steel pipes varies from $6 \mathrm{~mm}$ to $10 \mathrm{~mm}$. $K=E A / L$ is the axial stiffness of the tower column unit, $A$ is the area of steel pipe, and $L$ is the unit length. The stiffness of the tower column unit installed with VEDs is shown in Table 4.

For the convenience of calculation and analysis, the ratio of the stiffness between each brace and each tower column is taken as 0.2 , and the loss factor of the VED is taken as 1.4. Then, the ratio of the equivalent energy storage stiffness of the VED to brace stiffness $\lambda$ can be calculated by equation (16), and the additional modal damping ratio $\xi_{a}$ of the transmission line tower installed with VEDs can be further gained. The stiffness of the $i$ th tower segment, the energy storage stiffness of the $i \mathrm{VED}$, and the energy dissipation stiffness of the $i$ VED are defined as

$$
\begin{aligned}
& K_{b i}=\alpha_{b i} K_{f i}, \\
& K_{d i}=\lambda_{i} K_{b i},
\end{aligned}
$$




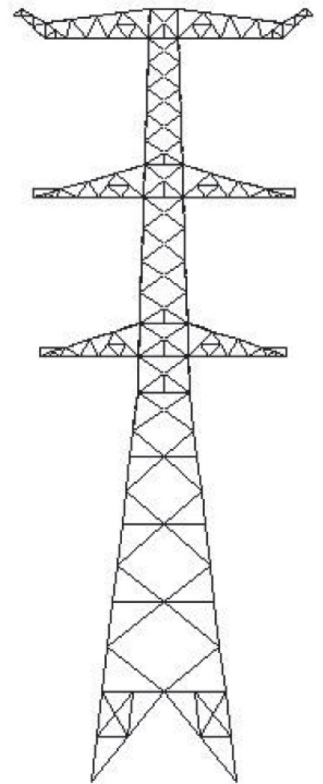

(a)

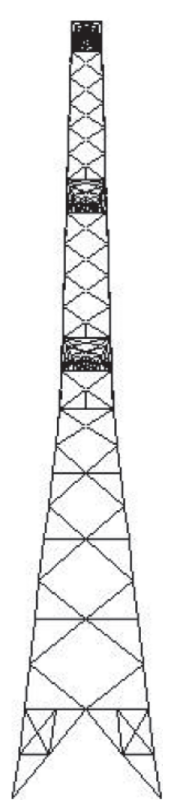

(b)

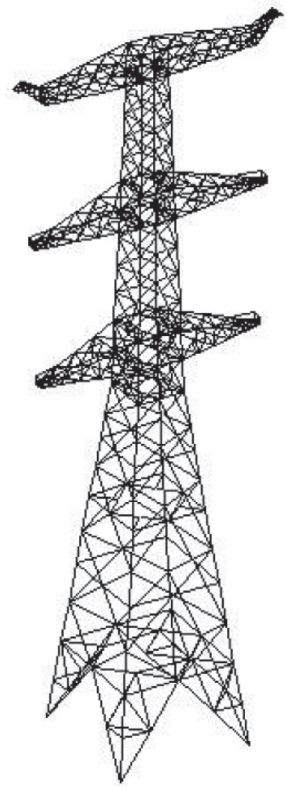

(c)

Figure 7: Finite element model of the transmission line tower: (a) $X-Z$ plane; (b) $Y-Z$ plane; (c) $X-Y-Z$ space.

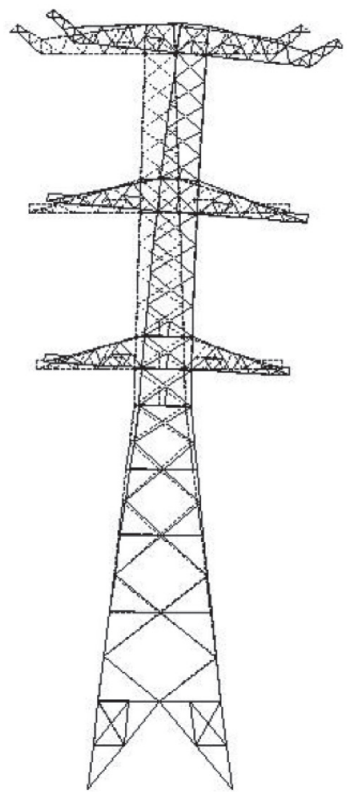

(a)

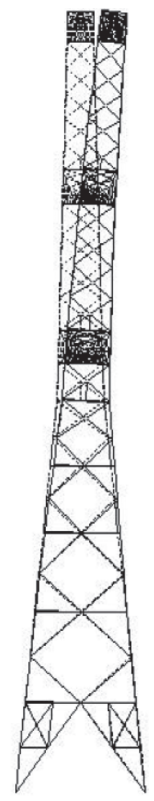

(b)

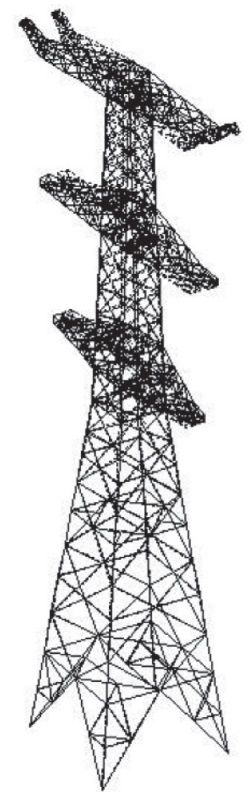

(c)

FIgURE 8: The first three mode shapes of the transmission line tower: (a) the first mode; (b) the second mode; (c) the third mode.

TABle 1: Properties of the transmission line tower.

\begin{tabular}{lcccc}
\hline Modal order & Frequency $f(\mathrm{~Hz})$ & Modal strain energy $W_{s}(\mathrm{~N} \cdot \mathrm{m})$ & Generalized mass $m$ (ton) & Characteristics of vibration mode \\
\hline 1 & 0.832 & 341896 & 25.00 & Transverse bending \\
2 & 0.849 & 337865 & 23.74 & Vertical bending \\
3 & 1.411 & 193149 & 4.91 & Torsion \\
\hline
\end{tabular}




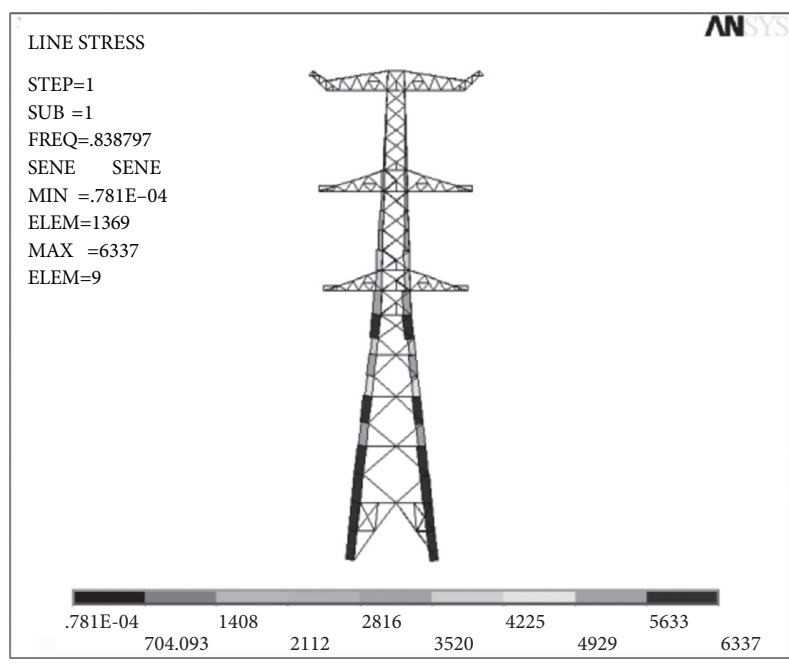

(a)

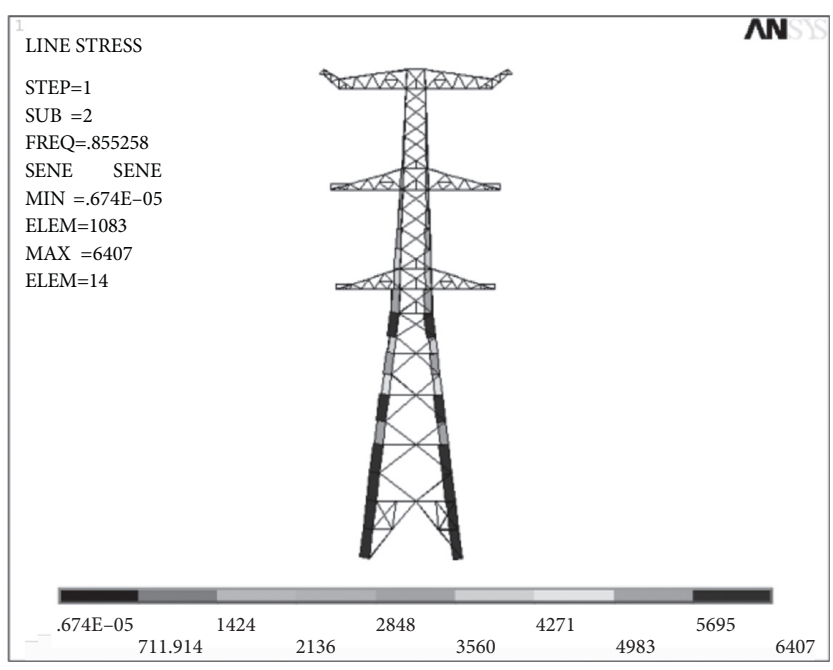

(b)

FIGURE 9: Strain energy distribution: (a) the first mode; (b) the second mode.

TABLE 2: Axial deformation of each main tower column for the first mode.

\begin{tabular}{lccc}
\hline Unit number & Unit length $(\mathrm{m})$ & Axial strain & Axial deformation (mm) \\
\hline 1 & 6.08 & 0.000616955 & 3.75 \\
2 & 6.08 & 0.000619991 & 3.77 \\
3 & 6.08 & 0.000636258 & 3.87 \\
4 & 6.11 & 0.000646764 & 3.95 \\
5 & 5.04 & 0.000648939 & 3.27 \\
21 & 5.61 & 0.000667406 & 3.75 \\
22 & 4.53 & 0.000670219 & 3.04 \\
23 & 4.48 & 0.000685088 & 3.07 \\
24 & 3.63 & 0.000688744 & 2.50 \\
25 & 5.07 & 0.000693175 & 3.52 \\
41 & 5.00 & 0.000678386 & 3.40 \\
42 & 4.40 & 0.000627275 & 2.76 \\
49 & 4.20 & 0.000754969 & 3.17 \\
50 & 4.20 & 0.000667704 & 2.81 \\
57 & 4.20 & 0.000623425 & 2.62 \\
58 & 4.20 & 0.000503736 & 2.12 \\
65 & 4.40 & 0.000589224 & 2.60 \\
73 & 3.40 & 0.000540314 & 1.84 \\
74 & 3.40 & 0.000544409 & 1.85 \\
76 & 3.40 & 0.000397533 & 1.36 \\
77 & 3.40 & 0.000261701 & 0.89 \\
\end{tabular}

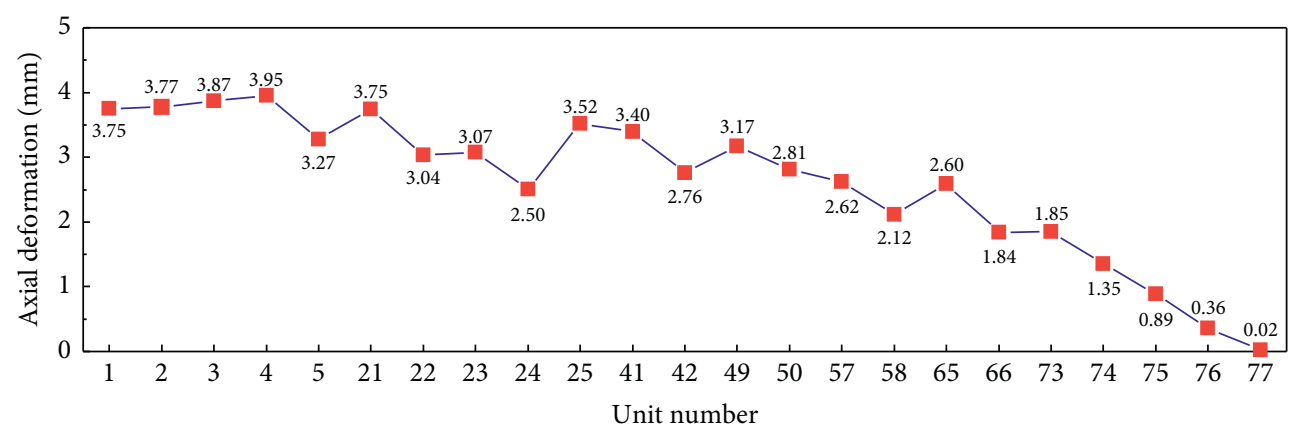

FIGURE 10: Variations of the axial deformation with the unit number for the first mode. 
TABLE 3: Installation scheme of VEDs.

\begin{tabular}{|c|c|c|c|c|c|c|}
\hline \multicolumn{4}{|c|}{ Unit number of the main tower column } & \multirow{2}{*}{$\begin{array}{l}\text { Axial deformation of the tower } \\
\text { column }(\mathrm{mm})\end{array}$} & \multirow{2}{*}{$\begin{array}{c}\text { Installation } \\
\text { scheme } 1\end{array}$} & \multirow{2}{*}{$\begin{array}{l}\text { Installation } \\
\text { scheme } 2\end{array}$} \\
\hline 1\# tower column & 2\# tower column & 3\# tower column & 4\# tower column & & & \\
\hline 1 & 6 & 11 & 16 & 3.75 & w/installed & w/installed \\
\hline 2 & 7 & 12 & 17 & 3.77 & $\mathrm{w} /$ installed & w/installed \\
\hline 3 & 8 & 13 & 18 & 3.87 & w/installed & w/installed \\
\hline 4 & 9 & 14 & 19 & 3.95 & $\mathrm{w} /$ installed & w/installed \\
\hline 5 & 10 & 15 & 20 & 3.27 & w/installed & w/installed \\
\hline 21 & 26 & 31 & 36 & 3.75 & w/installed & w/installed \\
\hline 22 & 27 & 32 & 37 & 3.04 & w/installed & w/installed \\
\hline 23 & 28 & 33 & 38 & 3.07 & w/installed & w/installed \\
\hline 24 & 29 & 34 & 39 & 2.50 & w/o installed & w/installed \\
\hline 25 & 30 & 35 & 40 & 3.51 & w/installed & w/installed \\
\hline 41 & 43 & 45 & 47 & 3.40 & w/installed & w/installed \\
\hline 42 & 44 & 46 & 48 & 2.76 & w/o installed & w/o installed \\
\hline 49 & 51 & 53 & 55 & 3.18 & w/installed & w/o installed \\
\hline 50 & 52 & 54 & 56 & 2.81 & w/o installed & w/o installed \\
\hline 57 & 59 & 61 & 63 & 2.62 & w/o installed & w/o installed \\
\hline 58 & 60 & 62 & 64 & 2.12 & w/o installed & w/o installed \\
\hline 65 & 67 & 69 & 71 & 2.60 & w/o installed & w/o installed \\
\hline 66 & 68 & 70 & 72 & 1.84 & w/o installed & w/o installed \\
\hline 73 & 78 & 83 & 88 & 1.85 & w/o installed & w/o installed \\
\hline 74 & 79 & 84 & 89 & 1.36 & w/o installed & w/o installed \\
\hline 75 & 80 & 85 & 90 & 0.90 & w/o installed & w/o installed \\
\hline 76 & 81 & 86 & 91 & 0.40 & w/o installed & w/o installed \\
\hline 77 & 82 & 87 & 92 & 0.02 & w/o installed & w/o installed \\
\hline
\end{tabular}

TABle 4: Stiffness of the main tower column unit installed with VEDs.

\begin{tabular}{|c|c|c|c|c|}
\hline \multirow[b]{2}{*}{ 1\# tower column } & \multicolumn{2}{|c|}{ Unit number of the main tower column } & \multirow[b]{2}{*}{ 4\# tower column } & \multirow{2}{*}{ Unit stiffness $(\mathrm{N} / \mathrm{m})$} \\
\hline & 2\# tower column & 3\# tower column & & \\
\hline 1 & 6 & 11 & 16 & 442038825 \\
\hline 2 & 7 & 12 & 17 & 442038825 \\
\hline 3 & 8 & 13 & 18 & 442038825 \\
\hline 4 & 9 & 14 & 19 & 440236029 \\
\hline 5 & 10 & 15 & 20 & 533066110 \\
\hline 21 & 26 & 31 & 36 & 456295733 \\
\hline 22 & 27 & 32 & 37 & 565187787 \\
\hline 23 & 28 & 33 & 38 & 571298462 \\
\hline 24 & 29 & 34 & 39 & 705064904 \\
\hline 25 & 30 & 35 & 40 & 504937712 \\
\hline 41 & 43 & 45 & 47 & 474209703 \\
\hline 42 & 44 & 46 & 48 & 538877694 \\
\hline 49 & 51 & 53 & 55 & 428210759 \\
\hline
\end{tabular}

$$
K_{d i}^{\prime}=\eta \lambda_{i} K_{b i}
$$

where $a_{b i}$ denotes the ratio of the brace stiffness to the tower column unit stiffness; $K_{f i}$ denotes the axial stiffness of the tower column; $\lambda_{i}$ denotes the ratio of the energy storage stiffness of the VED to the corresponding brace stiffness.

Equations (17)-(19) require that the parameters of VEDs in each tower section be different, which increases the difficulty of manufacturing dampers. Thus, the VEDs with the same parameters are used in this paper. Furthermore, the equivalent damping coefficient of the VED-brace system can be defined as

$$
C_{a}=\frac{K^{\prime}}{\omega}
$$

3.4. Calculation Method of Supplemental Modal Damping Ratio. There are mainly two methods used in calculating the additional modal damping ratio of the transmission line tower installed with VEDs: the modal strain energy method and the complex mode calculation method. The modal strain energy method is regarded as a simple method, which assumes that the tower frequency and vibration mode show less variation before and after installing VEDs. When the modal strain energy method is adopted, the additional 
modal damping ratio of the transmission line tower provided by VEDs can be expressed as

$$
\begin{aligned}
\xi_{a} & =\frac{E_{d}}{4 \pi E_{s}} \\
& =\frac{\pi \omega \sum_{i=1}^{n_{d}} C_{d i} u_{i}}{4 \pi E_{s}},
\end{aligned}
$$

where $E_{d}$ denotes the consumed energy by all VEDs in one cycle; $n_{d}$ is the number of VEDs; $u_{i}$ is the elongation at both ends of the VED; $E_{s}$ is the modal strain energy of the tower in one vibration cycle. It can be seen from equation (21) that the modal damping ratio can be calculated by the parameters of the VED and modal parameters such as the vibration mode and frequency of the transmission line tower.

When using the complex modal analysis method, it is necessary to establish the finite element model of the towerVED-brace system. The VED-brace system is regarded as a mechanical model with equivalent stiffness and equivalent damping, which is simulated with COMBIN14 element in ANSYS software. A total of 44 COMBIN14 elements are attached to both ends of the main tower column units of the transmission line tower. In the establishment of the COMBIN14 element, only one COMBIN14 element is needed to be added to the transmission tower node with VEDs, and the program automatically defaults that the two elements are in parallel mode. Accordingly, it is very convenient for establishing the finite element model of the tower-VED-brace system. In addition, the modal damping ratio can be further obtained by the complex modal analysis method. And the $r$ th vibration circular frequency and modal damping ratio of the transmission tower are computed as

$$
\begin{gathered}
\omega_{r}=\operatorname{Im}\left(\lambda_{r}\right), \\
\xi_{r}=\frac{-\operatorname{Re}\left(\lambda_{r}\right)}{\operatorname{Im}\left(\lambda_{r}\right)} .
\end{gathered}
$$

3.5. Influence of Installation Position and Parameters of VEDs on the Additional Modal Damping Ratio. The brace stiffness is taken as 0.1 to 0.2 times the tower column unit stiffness, and the loss factor $\eta$ of the VED is taken as 1.4. The ratio of the equivalent energy storage stiffness of the VED to brace stiffness $\lambda$ is calculated as 0.531 by equation (16). Based on the modal strain energy method and the complex modal analysis method, the variations of the first additional modal damping ratio $\xi_{1}$ with $\alpha_{b}$ provided by VEDs under two installation schemes are presented in Figure 11. It can be seen from Figure 11 that the first additional model damping ratio $\xi_{1}$ of provided by VEDs installed in accordance with installation scheme 1 is greater than that provided by VEDs installed in accordance with installation scheme 2. Hence, since installation scheme 1 is superior to installation scheme 2, installation scheme 1 will be used in the following research.

The brace stiffness $K_{b}$ is taken as 0.2 times of the axial stiffness of the tower column unit, and the loss factor $\eta$ of the
VED is taken as 1.4. The ratio of the equivalent energy storage stiffness of the VED to brace stiffness $\lambda$ is calculated as 0.531 by equation (16), and the value of $\lambda$ is further varied from 0.491 to 0.631 . Based on the modal strain energy method and the complex modal analysis method, the variations of the first additional modal damping ratio $\xi_{1}$ with $\lambda$ are illustrated in Figure 12. It can be found in Figure 12 that when the brace stiffness $K_{b}$ is a setting value, and the ratio of the equivalent storage of the VED to the brace stiffness is taken as the calculated value of equation (16), the first additional modal damping ratio $\xi_{1}$ of the transmission line tower obtained by the complex modal analysis method reaches the maximum value. Note that the first additional modal damping ratio $\xi_{1}$ predicted by the complex modal analysis method is greater than that of the modal strain energy method, and the value of the $\lambda$ corresponding to the first maximum additional modal damping ratio $\xi_{1}$ calculated by the complex modal analysis method is less than that of the first maximum additional modal damping ratio $\xi_{1}$ calculated by the modal strain energy method. In addition, the first additional modal damping ratio of the transmission line tower can be improved by increasing the bracing stiffness $K_{b}$.

The variations of the second additional modal damping ratio $\xi_{2}$ with $\lambda$ are further depicted in Figure 13. It is noteworthy that the variation of the second additional modal damping ratio $\xi_{2}$ with $\lambda$ is consistent with that of the first additional modal damping ratio $\xi_{1}$ with $\lambda$. It means that lower-order vibration control of the transmission line tower can be realized by controlling the first-order modal vibration of the transmission tower. Hence, the influences of the ratio of brace stiffness to tower column unit stiffness $\alpha_{b}$ and the loss factor $\eta$ on the first additional modal damping ratio $\xi_{2}$ of the transmission line tower are emphatically investigated in the following research.

The loss factor $\eta$ of the VED is taken as 1.4, and the ratio of the equivalent energy storage stiffness of the VED to brace stiffness $\lambda$ is calculated by equation (16). Based on the modal strain energy method and the complex modal analysis method, the variations of the first additional modal damping ratio $\xi_{1}$ with the ratio of brace stiffness to tower column unit stiffness $\alpha_{b}$ are shown in Figure 14. As shown in Figure 14, the first additional modal damping ratio $\xi_{1}$ increases linearly with the increase of the $\alpha_{b}$. In addition, the first additional modal damping ratio $\xi_{1}$ predicted by the complex modal analysis method is also greater than that of the modal strain energy method.

The ratio of brace stiffness to tower column unit stiffness $\alpha_{b}$ is taken as 0.2 , and the ratio of the equivalent energy storage stiffness of the VED to brace stiffness $\lambda$ is calculated by equation (16). Based on the modal strain energy method and the complex modal analysis method, the variations of the first additional modal damping ratio $\xi_{1}$ with the loss factor $\eta$ of the VED are shown in Figure 15. Note that the first additional modal damping ratio $\xi_{1}$ increases linearly with the increase of the $\eta$. Consistent with the result of Figure 14, the first additional modal damping ratio $\xi_{1}$ predicted by the complex modal 


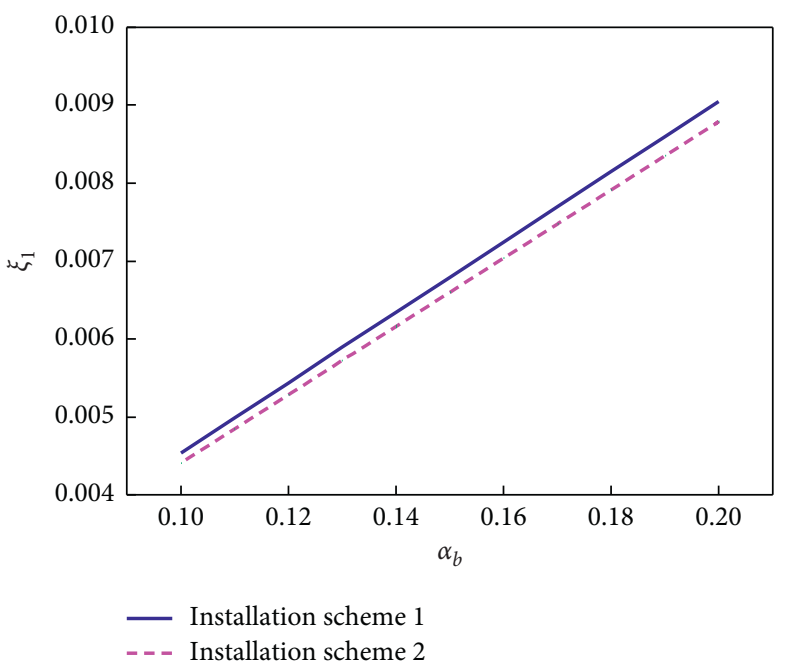

(a)

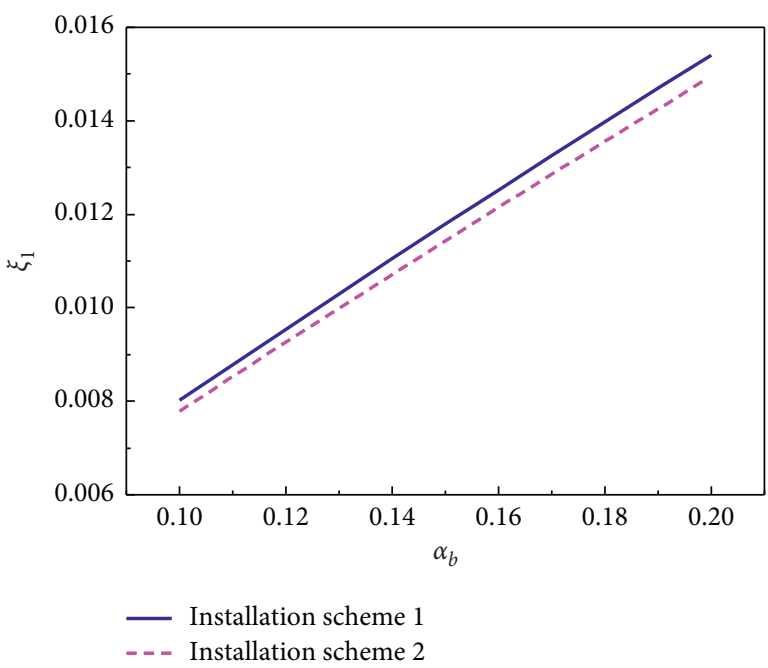

(b)

FIGURE 11: Variations of the first additional modal damping ratio $\xi_{1}$ with $\alpha_{b}$ under two installation schemes: (a) the modal strain energy method; (b) the complex modal analysis method.

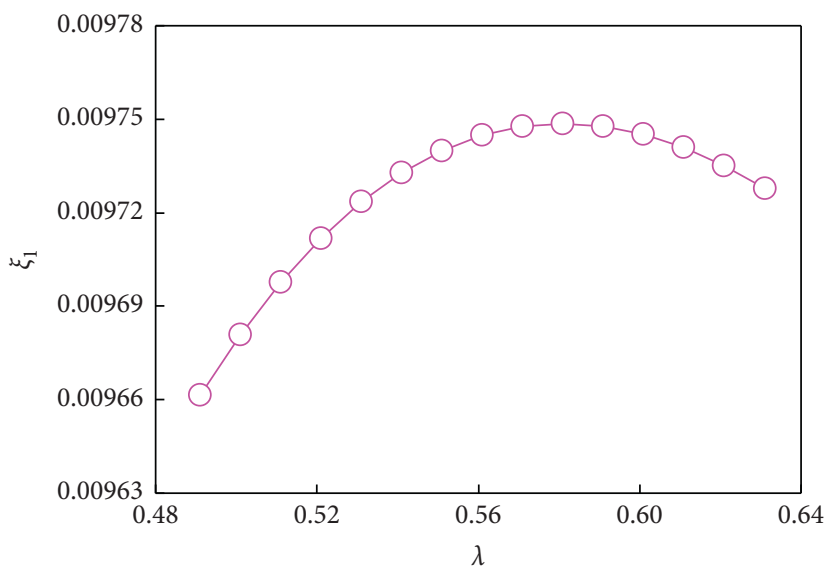

(a)

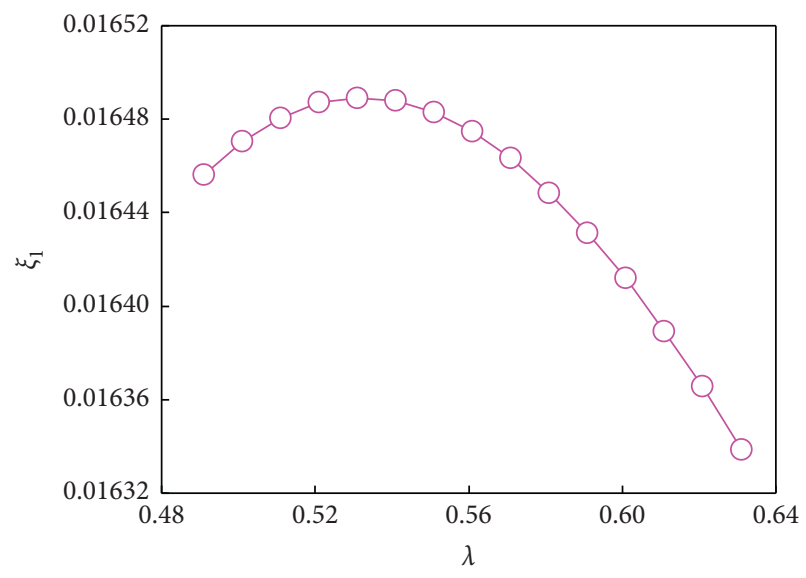

(b)

FIGURE 12: Variations of the first additional modal damping ratio $\xi_{1}$ with $\lambda$ : (a) the modal strain energy method; (b) the complex modal analysis method.

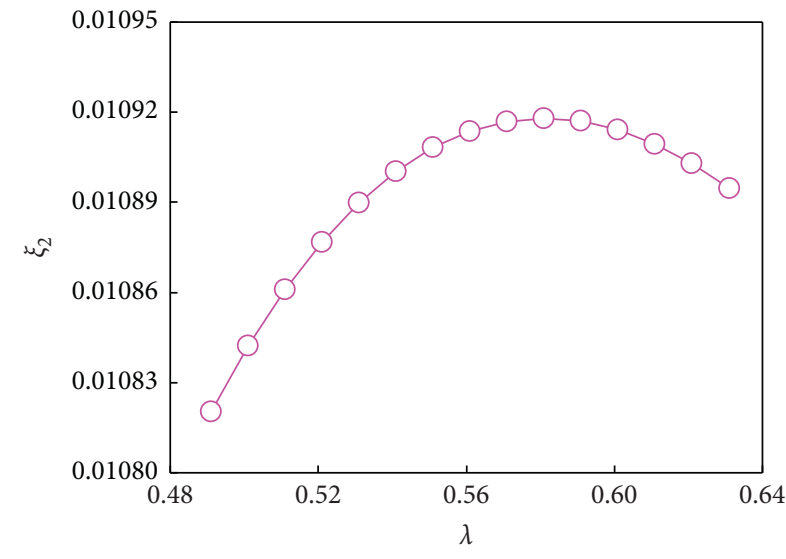

(a)

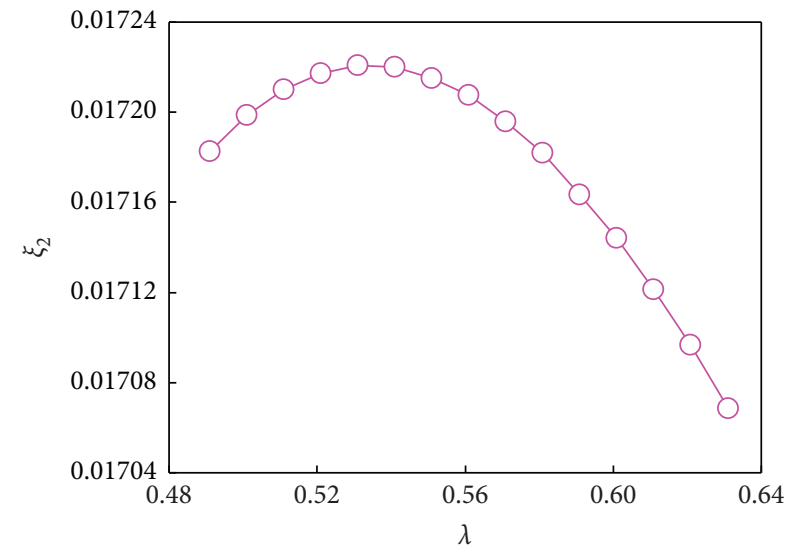

(b)

FIGURE 13: Variations of the second additional modal damping ratio $\xi_{2}$ with $\lambda$ : (a) the modal strain energy method; (b) the complex modal analysis method. 


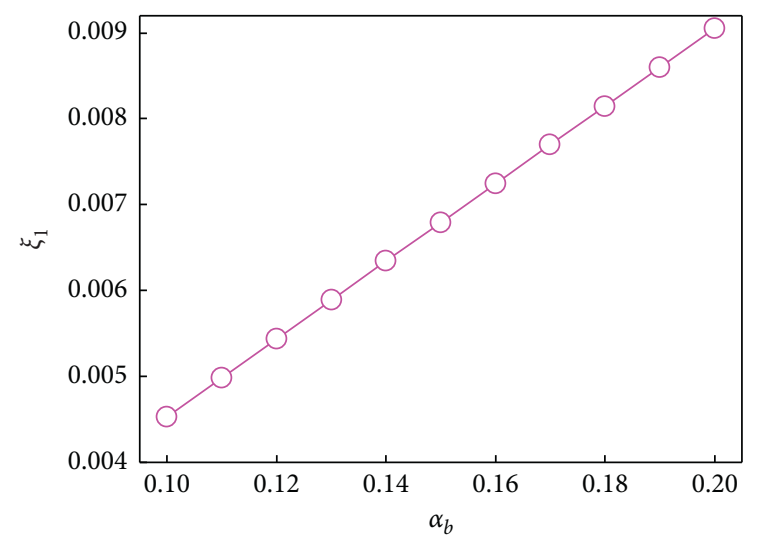

(a)

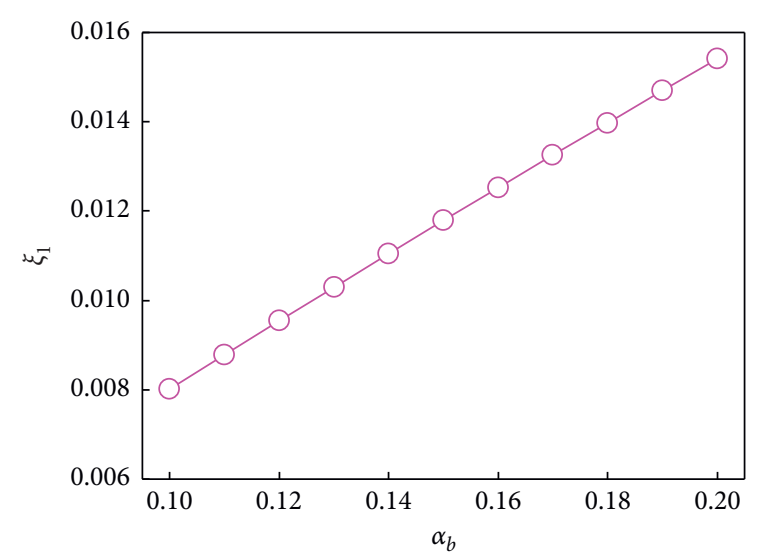

(b)

FiguRe 14: Variations of the first additional modal damping ratio $\xi_{1}$ with $\alpha_{b}$ : (a) the modal strain energy method; (b) the complex modal analysis method.

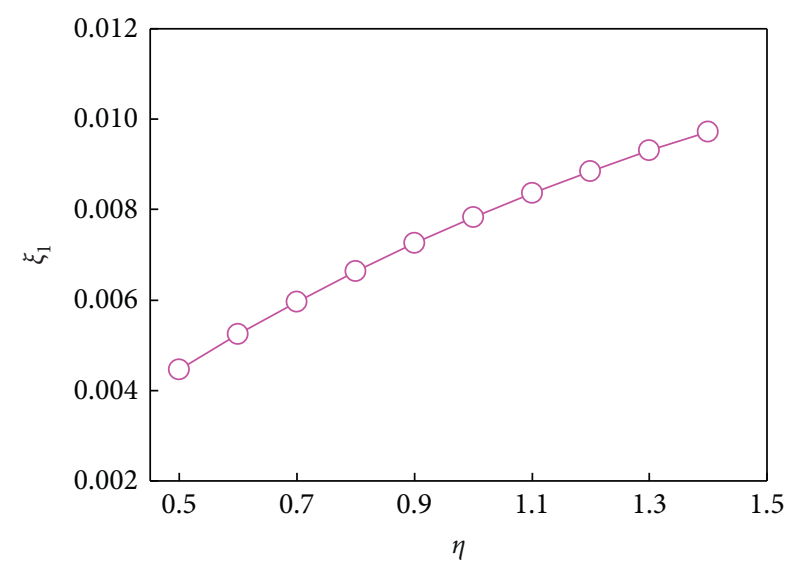

(a)

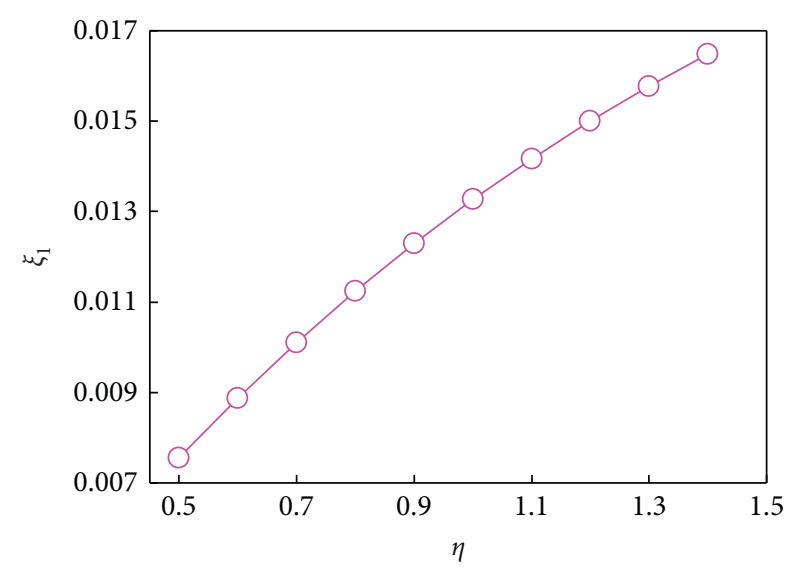

(b)

FIGURE 15: Variations of the first additional modal damping ratio $\xi_{1}$ with $\eta$ : (a) the modal strain energy method; (b) the complex modal analysis method.

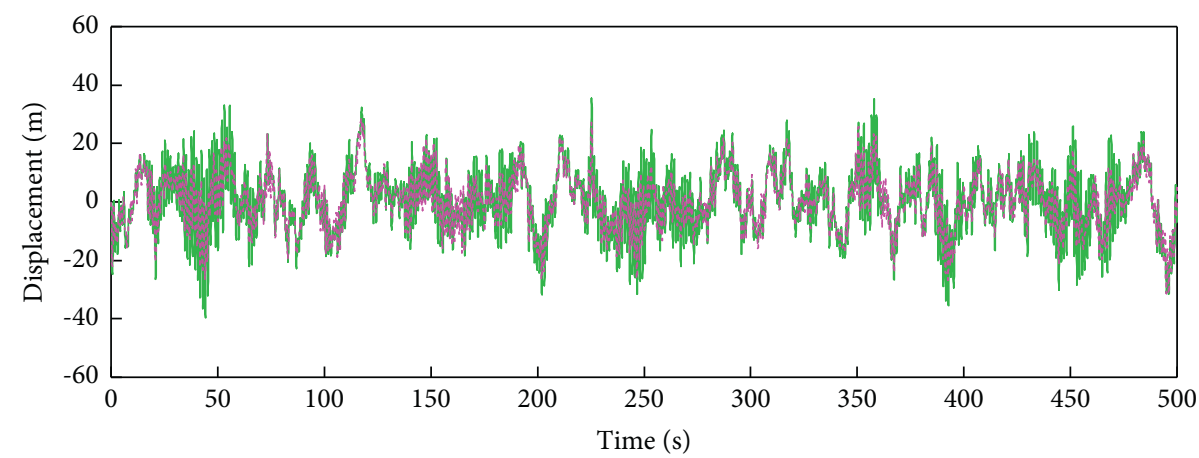

Without control

- - With viscoelastic dampers

FIGURE 16: Time history response of the top displacement of the transmission line tower. 


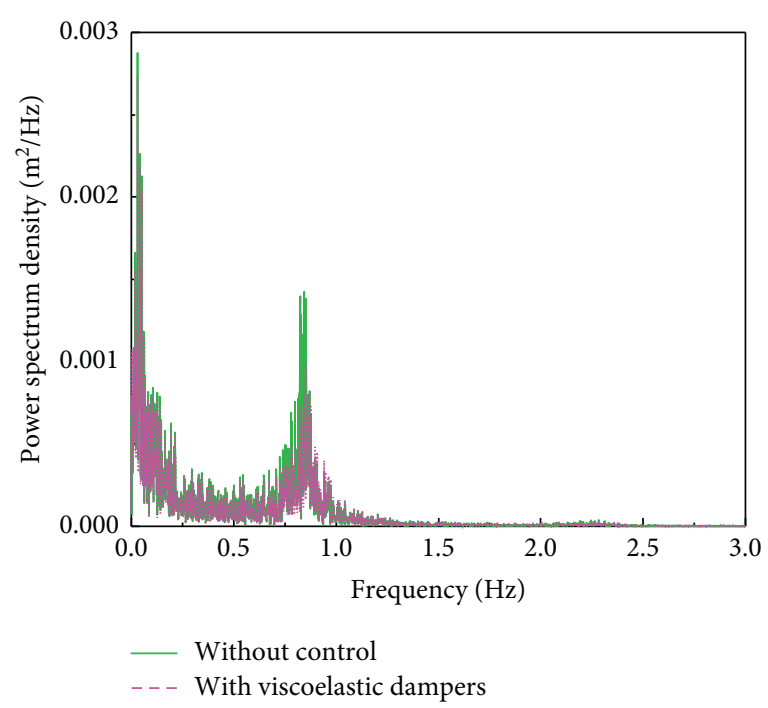

FIGURE 17: Power spectrum density of the displacement response.

analysis method is also greater than that of the modal strain energy method.

\section{Control Performance of VEDs for Wind- Induced Excitations}

The wind load in the vertical direction is applied to the transmission line tower without control and controlled by VEDs, respectively. The basic wind speed at $10 \mathrm{~mm}$ elevation is $30 \mathrm{~m} / \mathrm{s}$, and the site type is class B. The wind speed corresponding to each elevation is different, and the fluctuating wind speed time history at each height of the transmission line tower is simulated according to the harmonic synthesis method. In ANSYS, the buffeting force-time history is input along the main tower column of the transmission line tower, and the time domain response of the buffeting displacement is calculated by the time history integration method. The first two natural modal damping ratios of the transmission line tower are 0.02 . The transmission line tower is subjected to random vibration under fluctuating wind load in the range of $0 \mathrm{~s}$ to $500 \mathrm{~s}$.

Figure 16 illustrates the time history response of the displacement of the 481 nodes on the top of the transmission line tower along the wind direction without control and controlled by VEDs. The mean square value of the displacement on the top of the transmission line tower control by VEDs is $0.0091 \mathrm{~m}$, which is $18.9 \%$ lower than that of the transmission line tower without control $0.1124 \mathrm{~m}$. The power spectrum density of the displacement response of the transmission line tower without control and controlled by VEDs is shown in Figure 17. Compared with the transmission line tower without control, the transverse bending vibration energy of the transmission line tower control by VEDs presents a significant decrease.

\section{Conclusions}

This paper investigates the optimization of VEDs for vibration control of a transmission line tower subjected to wind excitations. The mechanical model of the VED-brace system was first established, and the maximum additional modal damping ratio of the transmission line tower attached with VEDs was calculated. Based on the finite element model of a two-circuit transmission line tower with VEDs, the influences of installation positions and parameters of VEDs on the additional modal damping ratio were clarified. In the end, the control performance of VEDs on the transmission line tower subjected to wind excitations was numerically demonstrated. The main conclusions are summarized as follows:

(1) The stiffness of the steel brace connected to a VED has a significant effect on the maximum additional modal damping ratio of the VED-brace system provided for the transmission line tower and the optimal parameters of the VED, which indicates that the stiffness of the steel brace cannot be ignored for the refined theoretical analysis and numerical simulation.

(2) The installation positions of VEDs dramatically influence the additional modal damping ratio of the transmission line tower. Studies indicate that the first additional modal damping ratio provided by VEDs installed in accordance with installation scheme 1 is greater than that provided by the VED installed in accordance with installation scheme 2 . Hence, installation scheme 1 is superior to installation scheme 2 . Besides that, the first additional modal damping ratio predicted by the complex modal analysis method is greater than that of the modal strain energy method.

(3) The increase of the brace stiffness and the loss factor helps to improve the vibration control performance of the transmission line tower with VEDs. The equivalent additional modal damping ratio provided by VEDs is increased with the brace stiffness and the loss factor, which presents a significant advantage in carrying out the optimal design of VEDs for mitigating tower vibrations.

(4) The VEDs present superior control performance on the top displacement of the transmission line tower as well as the transverse bending vibration energy. The mean square value of the displacement on the top of the transmission line tower control by VEDs is $0.0091 \mathrm{~m}$, which is $18.9 \%$ lower than that of the transmission line tower without control $0.1124 \mathrm{~m}$.

\section{Data Availability}

The data used to support the findings of this study are included within the article.

\section{Conflicts of Interest}

The authors declare no conflicts of interest.

\section{Acknowledgments}

This study was sponsored by Hunan Provincial Natural Science Foundation of China (Grant no. 2021JJ50143) and by Hunan Science and Technology Talent Promotion Project in China (Grant no. 2019TJ-Y08), which are greatly acknowledged. 


\section{References}

[1] T. Okamura, T. Ohkuma, E. Hongo, and H. Okada, "Wind response analysis of a transmission tower in a mountainous area," Journal of Wind Engineering and Industrial Aerodynamics, vol. 91, no. 1-2, pp. 53-63, 2003.

[2] E. P. U. S. Salunkhe and Y. M. Ghugal, "Analysis and design of three legged $400 \mathrm{kV}$ double circuit steel transmission line towers," International Journal of Civil Engineering \& Technology, vol. 4, no. 3, pp. 197-209, 2013.

[3] R. C. Battista, R. S. Rodrigues, and M. S. Pfeil, "Dynamic behavior and stability of transmission line towers under wind forces," Journal of Wind Engineering and Industrial Aerodynamics, vol. 91, no. 8, pp. 1051-1067, 2003.

[4] Y. Ming, Z. H. He, Y. C. Zhang, Y. C Liu, J. Yang, and Z. Y. Zhang, "Dynamic response of transmission lines crossing high-speed railway," IEEE Transactions on Power Delivery, vol. 2021, Article ID 3104902, 2021.

[5] M. Zhang, G. F. Zhao, L. Wang, and J. Li, "Wind induced coupling vibration effects of high voltage transmission tower line systems," Shock And Vibration, vol. 2017, Article ID 1205976, 34 pages, 2017.

[6] B. Asgarian, S. Dadras Eslamlou, A. Mehr, and M. Mehr M, "Progressive collapse analysis of power transmission towers," Journal of Constructional Steel Research, vol. 123, pp. 31-40, 2016.

[7] X. Fu and H.-N. Li, "Uncertainty analysis of the strength capacity and failure path for a transmission tower under a wind load," Journal of Wind Engineering and Industrial Aerodynamics, vol. 173, pp. 147-155, 2018.

[8] H. Patil, G. Doshi, N. P. Rao, D. Lakhpati, and V. Subramanian, "Failure analysis of transmission line tower: a case study," The IUP Journal of Structural Engineering, vol. 3, no. 1, pp. 20-27, 2010.

[9] F. G. A. Albermani and S. Kitipornchai, "Numerical simulation of structural behaviour of transmission towers," ThinWalled Structures, vol. 41, no. 2-3, pp. 167-177, 2003.

[10] B. Eltaly, A. Saka, and K. Kandil, "FE simulation of transmission tower," Advances in Civil Engineering, vol. 2014, pp. 343-355, Article ID 258148, 2014.

[11] E. Veg, M. Regodic, A. Joksimovic, and N. Gubeljak, "Development of the transmission tower virtual $3 \mathrm{D}$ model for structural analysis in ANSYS," FME Transaction, vol. 45, no. 2, pp. 232-235, 2017.

[12] H.-N. Li, S.-Y. Tang, and T.-H. Yi, "Wind-rain-induced vibration test and analytical method of high-voltage transmission tower," Structural Engineering \& Mechanics, vol. 48, no. 4, pp. 435-453, 2013.

[13] J. H. Park, B. W. Moon, K. W. Min, S. K. Lee, and C. K. Kim, "Cyclic loading test of friction-type reinforcing members upgrading wind-resistant performance of transmission towers," Engineering Structures, vol. 29, no. 11, pp. 435-453, Article ID 31853196, 2007.

[14] H. Z. Deng, S. Y. Zhu, Y. Chen, and Z. M. Wang, "Study on wind-induced vibration control of long span transmission line system," Journal of Building Structures, vol. 24, no. 4, pp. 60-64+75, 2003, in Chinese.

[15] H. Z. Deng, R. J. Si, X. Y. Hu, and C. Y. Duan, "Wind tunnel study on wind-induced vibration responses of a UHV transmission tower-line system," Advances in Structural Engineering, vol. 16, no. 7, pp. 1175-1185, 2013.

[16] L. Tian, Q. Wang, Q. Yu, and N. Xu, "Wind-induced vibration optimal control for long span transmission tower-line system," The Open Civil Engineering Journal, vol. 7, no. 1, pp. 159-163, 2013.
[17] Q. Xie and L. Sun, "Failure mechanism and retrofitting strategy of transmission tower structures under ice load," Journal of Constructional Steel Research, vol. 74, pp. 26-36, 2012.

[18] B. Chen, W. H. Guo, P. Y. Li, and W. P. Xie, "Dynamic responses and vibration control of the transmission towerline system: a state-of-the-art review," Science World Journal, vol. 2014, Article ID 538457, 20 pages, 2014.

[19] D. M. Lima, P. A. L. Yanez, and M. A. Pareira Ma, "Vibration control device for steel tubular towers of horizontal axis wind turbines," Latin American Journal of Solids and Structures, vol. 16, no. 6, pp. 1-21, 2019.

[20] S. Roy and C. K. Kundu, "State of the art review of wind induced vibration and its control on transmission towers," Structure, vol. 29, pp. 254-264, 2021.

[21] L. Suresh and K. M. Mini, "Effect of multiple tuned mass dampers for vibration control in high-rise buildings," Practice Periodical on Structural Design and Construction, vol. 24, no. 4, Article ID 04019031, 2019.

[22] F. Rahimi, R. Aghayari, and B. Samali, “Application of tuned mass dampers for structural vibration control: a state-of-theart review," Civil Engineering Journal, vol. 6, no. 8, pp. 1622-1651, 2020.

[23] L. Tian and Y. Zeng, "Parametric study of tuned mass dampers for long span transmission tower line system under wind loads," Shock and Vibration, vol. 2016, Article ID 4965056, 11 pages, 2016.

[24] X. Lei, W. P. Xie, M. Nie, H. W. Niu, J. L. Chen, and Y. X. Wang, "Development and application of a new type of TMD in transmission tower vibration reduction," Journal of Vibration and Shock, vol. 38, no. 13, pp. 73-80, 2019, in Chinese.

[25] B. Zhao, D. Wu, and Z. Lu, "Shaking table test and numerical simulation of the vibration control performance of a tuned mass damper on a transmission tower," Structure and Infrastructure Engineering, vol. 17, no. 8, pp. 1110-1124, 2021.

[26] B. Chen, J. Zheng, and W. Qu, "Control of wind induced response of transmission tower line system by using magnetorheological dampers," International Journal of Structural Stability and Dynamics, vol. 9, no. 4, pp. 661-865, 2009.

[27] B. Chen, X. Xiao, P. Li, and W. Zhong, "Performance evaluation on transmission tower-line system with passive friction dampers subjected to wind excitations," Shock And Vibration, vol. 2015, Article ID 310458, 13 pages, 2015.

[28] C. Zeng, D. X. Hao, and L. Q. Hou, "Research on calculation of equivalent damping ratio of electrical transmission towerline system with viscoelastic dampers," Advanced Materials Research, vol. 1064, pp. 115-119, 2014. 